\title{
Tidal project worth support
}

SitTING somewhere in the Department of Energy is a proposal by a team of engineers known as the Severn Barrage Group for a major study of the feasibility of extracting substantial amounts of tidal energy from the flow of water in the Bristol Channel/Severn Estuary region. The outcome of the request for $£ 1.2$ million to do 18 months' investigative work will be watched with great interest by all who have a concern that no energy option should be closed out without some pretty sophisticated analysis and without an extended time being available for public debate.

Tide mills are a pretty old concept. T. L. Shaw, writing on the Severn scheme in Nature, 249, 730 (1974), remarks that they can be traced back to 1180 , and the idea of harnessing the unusually high tidal range in the Severn Estuary (mean range 7 metres) was first given detailed engineering study as far back as 1933. Even when nature conspires to provide as favourable a site as the Severn Estuary, however, everyone knows that tidal energy suffers from the severe defect that if turbines are simply driven by the flow of water into and out of the estuary, the periodicity of the daily demand for electricity is only spasmodically in phase with the times at which tidal power can make a useful contribution. There are enough thermal generating sets around the country suffering reduced efficiency because of this daily demand cycle for there to be little enthusiasm simply for the addition of another cyclic term, and, what's more, one with a 29 -day spring/neap periodicity to bedevil operating conditions even more. It is for these reasons that the French, who have successfully run a 240-MW tidal generator at La Rance, Brittany, for many years, have never proceeded to the larger scheme for which La Rance was the pilot.

The Severn Estuary scheme as now proposed would, however, not be tied to delivering energy in phase with the tides, but would be part of an integrated scheme providing pump-storage facilities for conventional thermal stations. A barrage would close off the estuary between Cardiff and Weston; above it would be the primary basin in which the water level would fluctuate between the present mean sea level and the high springtide level-that is, there would be no flooding of land. Just seaward of the barrage, in deep water, would be a secondary basin, maybe 5 kilometres across. Water from this basin could be pumped up into the primary basin using electric power from thermal power stations. Electricity would be generated both by the fall of seawater at high tide into the (drained) secondary basin and also by the fall of water in the primary basin back into the sea at low tide. Electricity would be generated during the daytime and consumed in pumping at night. In this way a scheme combining tidal energy extraction and pumped storage would take electricity from thermal stations at times at which they might otherwise have to close down.

Rough estimates put the cost at $£ 2,000$ million to generate around 4,000 MW during the day (nearly a tenth of the nation's load at present)-in itself rather an expensive investment, though less so when the advantages of the pumped storage scheme are incorporated and consideration is taken of the price, or lack of it, of fuel.

Until now studies on the Severn Barrage have been conducted at a fairly academic level, and only recently has much serious work been done on the obviously major environmental impact; a cursory examination of material published suggests no overwhelming environmental objections. The time looks ripe therefore for a much more extensive feasibility study. Around $£ 1$ million has recently been committed to exploratory research for geothermal energy sources which seem less likely to make a major impact on the nation's energy requirements; a similar sum on tidal energy and the effect that the scheme could have on the environment does not look to be out of line.

If a study is funded and finds that the case for some sort of barrage is strong and that environmental objections can be met, there is still bound to be one major question mark hanging over the project. Once into such a scheme there is little benefit gained in calling it off on the way to completion. If costs go awry, if major problems arise, if the energy scene changes dramatically, there is little that a half-completed barrage can be used for. This will doubtless be used as ammunition by those who have a distaste for large technological projects, so it would be more than usually necessary that both the feasibility survey be done exceptionally well, and that the politicians who make the ultimate decision be thoroughly open with the public about the basis of their decision-since they probably won't be around at the time when nerves are being tested. 